\title{
Universiteit
}

Leiden

The Netherlands

\section{Pelvic floor dysfunction is not a risk factor for febrile urinary tract infection in adults}

Nieuwkoop, C. van; Voorham-van der Zalm, P.J.; Laar, A.M. van; Elzevier, H.W.; Blom, J.W.;

Dekkers, O.M.; ... ; Dissel, J.T. van

\section{Citation}

Nieuwkoop, C. van, Voorham-van der Zalm, P. J., Laar, A. M. van, Elzevier, H. W., Blom, J. W., Dekkers, O. M., ... Dissel, J. T. van. (2010). Pelvic floor dysfunction is not a risk factor for febrile urinary tract infection in adults. Bju International, 105(12), 1689-1695.

Retrieved from https://hdl.handle.net/1887/117640

Version: $\quad$ Not Applicable (or Unknown)

License: $\quad$ Leiden University Non-exclusive license

Downloaded from: https://hdl.handle.net/1887/117640

Note: To cite this publication please use the final published version (if applicable). 


\section{BIT Pelvic floor dysfunction is not a risk factor for febrile urinary tract infection in adults}

Cees van Nieuwkoop, Petra J. Voorham-van der Zalm*, Anne-Marike van Laar, Henk W. Elzevier*, Jeanet W. Blom ${ }^{+}$, Olaf M. Dekkers ${ }^{\ddagger}$, Rob C.M. Pelger*, A. Mieke van Aartrijk-van Dalen, Marjanne C. van Tol and Jaap T. van Dissel Department of Infectious Diseases, ${ }^{*}$ Urology, ${ }^{+}$Public Health and Primary Care and ${ }^{*}$ Clinical Epidemiology, Leiden University Medical Center, Leiden, the Netherlands

Accepted for publication 12 August 2009

Study Type - Therapy (case control) Level of Evidence $3 b$

\section{OBJECTIVE}

To determine whether pelvic floor dysfunction (PFD) might be a risk factor for or consequence of febrile urinary tract infection (UTI), as UTI in adults is a common infection in which an underlying urological abnormality is often considered, and as in children, PFD is also thought to have a pathophysiological role in adults with UTI.

\section{PATIENTS AND METHODS}

A multicentre case-control study was conducted at 26 primary-care centres and at six Emergency Departments of regional hospitals. Cases were consecutive patients aged $\geq 18$ years, who presented with febrile
UTI. Controls were randomly selected subjects who visited their general practitioner for reasons other than UTI or fever. A validated pelvic floor questionnaire (the Pelvic Floor Inventories Leiden, PelFls) was used to assess pelvic floor function.

\section{RESULTS}

Between October 2006 and December 2007, 153 cases were included; of these, the completed questionnaires of 102 (response rate $67 \%$ ) were compared to those of 100 of 110 (response rate 91\%) controls. The median age of cases and controls was 65 and 58 years, respectively; $40 \%$ of cases and controls were men. The percentage of PelFls outcomes consistent with PFD were comparable between cases and controls, at $21 \%$ vs 23\%, respectively (odds ratio 0.9, $95 \%$ confidence interval, $\mathrm{Cl}, 0.4-1.78)$. In the multivariate analysis, comorbidity (odds ratio $4.9,95 \% \mathrm{Cl} 2.2-11.1)$ and a history of UTI (odds ratio 2.5, 95\% Cl 1.0-6.1) were independent significant risk factors for febrile UTI, whereas PFD was not (odds ratio 1.0, 0.5-2.2). Within the group of cases, PFD was not associated with bacteriuria during assessment of PelFls (odds ratio 1.1, 95\% Cl 0.4-3.5) and inversely related to a history of UTI within the previous year (odds ratio 0.2, 0.1-0.9).

\section{CONCLUSIONS}

PFD is common among adults but it does not seem to be a risk factor for febrile UTI.

\section{KEYWORDS}

pelvic floor dysfunction, acute pyelonephritis, adults, urinary tract infection

\section{INTRODUCTION}

UTIs are among the most common bacterial infections in humans and there is ample knowledge about its management. Fever in UTI suggests the presence of acute pyelonephritis that causes substantial morbidity and mortality, with estimated direct and indirect costs of $\$ 2.14$ billion in the USA in 2000 [1-3].

For the pathophysiology of UTIs, in the past decades there has been successful molecular research that has unravelled the main determinants of bacterial virulence and overall host resistance [4-9]. However, the significance of these molecular findings for individual patient management remains unclear, and purposeful integration into clinical practice guidelines has not been straightforward. In clinical practice, a diagnostic urological evaluation is considered after complicated or recurrent UTIs and strongly recommended if underlying urological disorders are suspected, especially in men and postmenopausal women [10-13]. In general, a urological evaluation relies on a thorough search for anatomical or functional disorders but the yield for detecting new abnormalities is rather low $[14,15]$.

\section{Pelvic floor dysfunction (PFD) is a general} term for functional clinical problems affecting urinary, rectal and/or sexual function [16]. In children, PFD, also termed dysfunctional voiding or dysfunctional elimination syndrome, is widely accepted as a major contributor to the development of UTIs, and pelvic muscle floor rehabilitation is the standard of treatment for many young patients [17]. It has been suggested that PFD might also explain the occurrence of complicated UTIs in cases with a normal urinary tract [18]. However, in adults the role of PFD in UTIs has only been described in selected subgroups, predominantly young women with recurrent UTIs [19-22]. To our knowledge there have been no comparative studies that assessed the question of whether PFD is a risk factor in adults with complicated UTI.

For this reason, we conducted a case-control study of community-acquired febrile UTI in an 
unselected population. The aim of the study was to determine whether PFD might be a risk factor for or consequence of febrile UTI. A validated questionnaire, the Pelvic Floor Inventories Leiden (PelFls), including questions about micturition, defecation and sexual function, was used to evaluate PFD [23].

\section{PATIENTS AND METHODS}

We conducted a multicentre case-control study; cases were recruited at six emergency departments of regional hospitals and 26 neighbouring primary healthcare centres. Consecutive patients (men and women) presenting with a presumptive diagnosis of febrile UTI, and those who met the following entry criteria and provided written informed consent, were included.

Inclusion criteria for cases were age $\geq 18$ years, fever (rectal/ear temperature of $\geq 38.2{ }^{\circ} \mathrm{C}$ ) and/or a history of fever and chills within $24 \mathrm{~h}$ before presentation, at least one symptom of UTI (dysuria, frequency, urgency and suprapubic, perineal or flank pain) and leukocyturia defined as a positive leukocyte esterase dipstick test or the presence of more than five leukocytes per high-power field in a centrifuged sediment.

Controls were consecutive patients aged $\geq 18$ years who consulted their primary healthcare physician for reasons other than fever or UTI. They were recruited at random selected dates at primary healthcare centres within the same region as recruitment of cases.

Exclusion criteria at presentation with febrile UTI were polycystic kidney disease, haemoor peritoneal dialysis, a history of kidney transplantation or an expected inability to obtain follow-up (e.g. language barrier). As for cases, the PelFls was obtained 28-32 days after presentation with a febrile UTI, and the following exclusion criteria were applied: patients with indwelling urinary catheter, urostomy, recent pelvic surgery, spinal cord lesions or those who developed cognitive dysfunction or became pregnant. For controls, all of the above exclusion criteria also applied. The study was approved by the local ethics committees (protocol number P06.061).

Baseline demographic, clinical and microbiological data were collected by certified research nurses or the clinical investigators (C.v.N., A.v.L.) who visited all primary-care patients directly after notification. Data from patients included at the emergency departments were collected from the medical record, completed with an interview by telephone or at the bedside.

Blood and urine cultures were taken before starting antimicrobial therapy within $2 \mathrm{~h}$ of notification, and were assessed using standard microbiological methods. Cases were treated for 10-14 days with antimicrobials for febrile UTI. Cases were visited 28-32 days after presentation with febrile UTI to assess the clinical and microbiological outcome. A midstream urine specimen was cultured and all cases were asked to complete the PelFls. Controls were visited once after notification to collect demographic and microbiological data, including urine cultures, and to complete the PelFls.

\section{All questionnaires were evaluated} independently by two urologists (H.W.E., R.C.M.P.) who were unaware of all other data except for gender. They dichotomized the outcomes of the questionnaires to either suspected presence or absence of PFD. The cases with interobserver disagreement were re-evaluated and discussed by these two urologists, who adjudicated the final outcome based on their consensus. Examples of questions of the PelFls are listed in the Appendix.

Comorbidity was defined as the presence of any urinary tract disorder, heart failure, cerebrovascular disease, renal insufficiency, diabetes mellitus, malignancy or chronic obstructive pulmonary disease for which the patient is prescribed medication and/or consults a hospital-based medical specialist.

Urinary tract disorder was defined as any history of anatomical urological abnormality (e.g. BPH, nephrectomy, re-implantation of ureter, VUR, bladder carcinoma, urethral stricture) except nephrolithiasis. Significant bacteriuria was defined as a monoculture of $\geq 10^{3}$ colony-forming units $/ \mathrm{mL}$ of urine [24].

Descriptive analysis included means or percentages with $95 \% \mathrm{Cls}$, or the median (range), as appropriate. Inter-observer agreement for the accurate determination of the presence or absence of PFD was assessed by using the Cohen $\mathrm{\kappa}$-test, in which a $\kappa$-value of 0.41-0.60 corresponds to fair agreement, $0.61-0.80$ to good agreement, $0.81-0.92$ to very good agreement and $0.93-1.00$ to excellent agreement [25]. For comparison of cases and controls, we used multivariable logistic regression to calculate the odds ratios (ORs) with their 95\% Cls for categorical variables. In addition to age and sex we adjusted for comorbidity and a history of UTIs as potential confounders. This included the evaluation of potential interaction terms between these factors. Finally, within the group of cases, those with suspected PFD were compared to those without using chi-square tests to assess univariable associations. Multivariable analysis for this subgroup analysis was not done because of the small sample size. For all statistical tests, a two-tailed $P<0.05$ was considered to indicate statistical significance.

\section{RESULTS}

Between October 2006 and October 2007, 178 patients with febrile UTI were enrolled in the study and 153 met the criteria for case definition. Of these 153 cases, 51 could not be evaluated because they were lost to followup, died, refused or for other reasons (Fig. 1). The remaining 102 cases (response rate 67\%) were compared to the 51 excluded cases; there were no differences with respect to gender, diabetes mellitus or history of UTIs, but the excluded cases were older (median age 75 vs 65 years, $P=0.002$ ) and they had an underlying urinary tract disorder more often (39\% vs $18 \%, P=0.013$ ). The PelFls questionnaires were analysed and compared to those of the 100 controls of 110 asked (response rate 91\%). Most controls consulted their primary healthcare physician because of cardiovascular risk management or musculoskeletal symptoms. The median age of cases and controls was 66 and 58 years, respectively; $60 \%$ were women. Cases were more likely to have comorbidity, urological disorders, a history of UTIs and bacteriuria during completion of the questionnaire (Table 1).

Besides fever and symptoms of UTI at presentation with febrile UTI, $62 \%$ of cases noticed flank pain, 66\% had shaking chills and 28\% were pre-treated for UTI. Cases were empirically treated with oral ciprofloxacin as outpatients in 39\%, while the remaining 61\% were admitted and received a $\beta$-lactam \pm aminoglycoside i.v. 
FIG. 1. Enrolment of participants in the study.

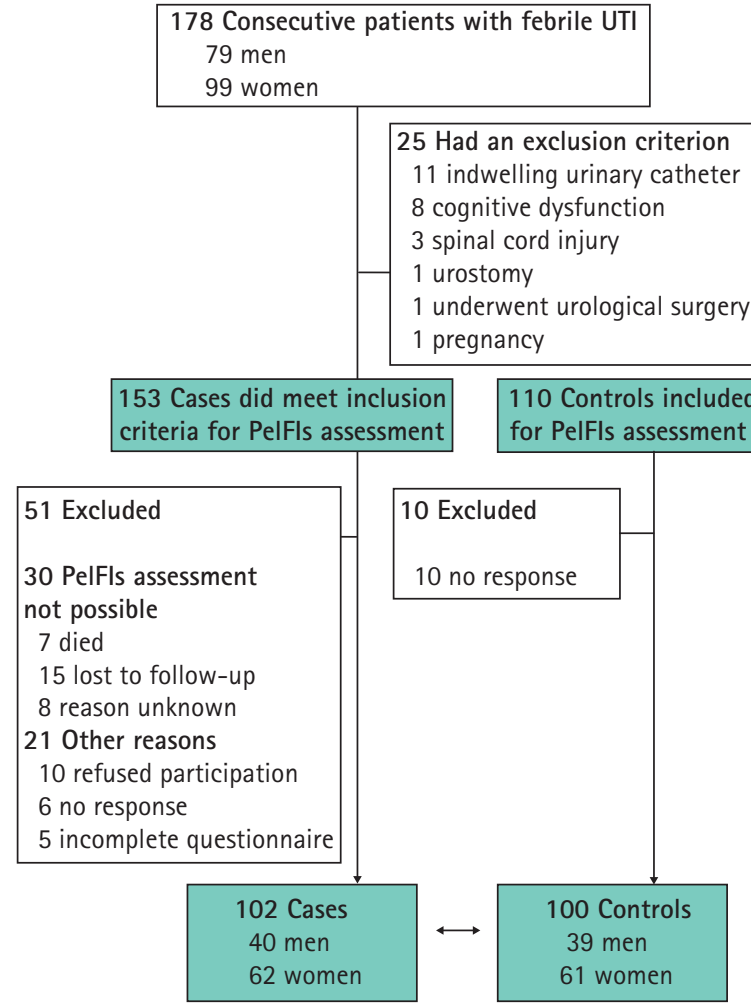

TABLE 1 The baseline characteristics of the 102 cases and 100 controls

Characteristic

Median (interquartile range) age, years

Men

Mean (SD) body mass index, $\mathrm{kg} / \mathrm{m}^{2}$

Smoking

Comorbidity:

Diabetes mellitus

Urinary tract disorder

History of UTIS

Bacteriuria during PeIFls

*In four cases no urine sample was cultured. Data are n (\%) unless otherwise indicated.

\begin{tabular}{ll} 
Cases & Controls \\
\hline $65(44-75)$ & $58(48-67)$ \\
$40(40)$ & $39(39)$ \\
$25(4)$ & $26(4)$ \\
$17(17)$ & $14(14)$ \\
& \\
$19(19)$ & $8(8)$ \\
$18(18)$ & $10(10)$ \\
$51(50)$ & $21(21)$ \\
$23 / 98^{*}(24)$ & $4(4)$
\end{tabular}

Urine samples, cultured at presentation with febrile UTI, were available in 98 cases; 66 (67\%) had significant bacteriuria (80\% Escherichia coli). Of the remaining 32 cases without significant bacteriuria, 17 could be explained by antimicrobial pretreatment.

Blood cultures were available in 98 cases; 17

$(17 \%)$ had bacteraemia, of which $88 \%$ were E. coli.

After recovery of febrile UTI, in 98 cases a repeat urinary culture was available
28-32 days after the initial presentation with febrile UTI. Of these, 22 (22\%) revealed significant bacteriuria (68\% E. coli). One of these 22 cases had recurrent UTI symptoms; the remaining 21 with bacteriuria were considered asymptomatic.

The interobserver agreement between the two urologists for interpreting the PelFls questionnaires was good ( $\kappa=0.62$,

$P<0.001)$. The presence of PFD, as assessed by the PelFIs questionnaire, was lower among cases than controls but this was not statistically significant, at $21 \%$ vs $23 \%$, respectively (OR 0.9, 95\% $\mathrm{Cl} 0.4-1.7)$. This OR was the same after adjusting for age and sex. As this could be different for men and women we compared the 62 women with the 62 women controls; the OR for PFD associated with febrile UTI, was 0.7 (95\% Cl 0.3-1.6).

Other risk factors for the presence of febrile UTI were comorbidity, urinary tract disorders and previous UTIs (Table 2). Independent significant risk factors for febrile UTI in the multivariable analysis were comorbidity (OR $4.9,95 \% \mathrm{Cl} 2.2-11.1)$, a history of UTI (OR 2.5, 95\% Cl 1.0-6.1) and a history of UTI the previous year (OR 3.0, 95\% Cl 1.1-8.2).

Among the 102 cases, a history of urinary tract disorder, which was present predominantly in men, was associated with the presence of PFD (OR 3.7, 95\% Cl 1.1-12.1, adjusted for age and sex). Age $>75$ years and a history of UTI within the previous year were both inversely associated $(0.3,0.06-1.2$; and $0.2,0.1-0.9$, respectively). The presence of bacteriuria during assessment of the PelFls (OR 1.1, 95\% Cl 0.4-3.5) was not associated with the presence of PFD.

\section{DISCUSSION}

To our knowledge, the present study is the first to investigate the relationship between PFD and febrile UTI in adults which, in this study setting, might also be interpreted as acute pyelonephritis [2,3]. We found that PFD is common but seems to be neither a risk factor for nor a consequence of febrile UTI in adults. In patients who recovered from febrile UTI, 21\% were suspected to have PFD, compared to $23 \%$ in a general adult population seeking primary healthcare. As this was assessed shortly after recovery from a febrile UTI, we conclude that PFD also does not seem to be a consequence of febrile UTI.

To assess the presence of PFD we used a previously validated questionnaire, the PelFIs, which is not the reference standard to detect PFD [23]. However, if there were any standard to assess PFD, the diagnostics used would be complex and often require multiple, difficult to interpret, confirmatory tests [26]. In our experience, based on this questionnaire, patients can be stratified into those suspected not suspected to have PFD. Suspected cases are subjected to further analysis of the pelvic floor and PFD can thus be confirmed in 77\% 


\begin{tabular}{|c|c|c|c|c|c|}
\hline \multirow[b]{2}{*}{ Factor } & \multirow[b]{2}{*}{$\begin{array}{l}\text { Cases } \\
(102)\end{array}$} & \multirow[b]{2}{*}{$\begin{array}{l}\text { Controls } \\
(100)\end{array}$} & \multicolumn{3}{|c|}{ OR $(95 \% \mathrm{Cl}) ; P$} \\
\hline & & & $\begin{array}{l}\text { Unadjusted } \\
\text { univariable }\end{array}$ & $\begin{array}{l}\text { Adjusted for } \\
\text { age and sex }\end{array}$ & $\begin{array}{l}\text { Adjusted for age, sex, } \\
\text { comorbidity and history of UTI }\end{array}$ \\
\hline$\overline{P F D}$ & $21(21)$ & $23(23)$ & $0.9(0.4-1.7)$ & $0.8(0.4-1.6)$ & $1.0(0.5-2.2) ; 0.95$ \\
\hline \multicolumn{6}{|l|}{ Demographic } \\
\hline Age $\geq 50$ years & $72(71)$ & $69(69)$ & $1.1(0.6-2.0)$ & $1.1(0.6-2.0)^{*}$ & $0.8(0.4-1.7) ; 0.58$ \\
\hline Men & 40 (39) & 39 (39) & $1.0(0.6-1.8)$ & $0.9(0.5-1.7)+$ & $1.5(0.7-3.2) ; 0.25$ \\
\hline \multicolumn{6}{|l|}{ Comorbidity } \\
\hline Any comorbidity & $48(47)$ & $19(19)$ & $3.8(2.0-7.1)$ & $4.1(2.0-8.1)$ & $4.9(2.2-11.1) ;<0.001$ \\
\hline Urinary tract disorder & $18(18)$ & $10(10)$ & $1.9(0.8-4.4)$ & $1.9(0.8-4.5)$ & $0.6(0.2-1.8) ; 0.39$ \\
\hline Diabetes mellitus & $19(19)$ & $8(8)$ & $2.6(1.1-6.3)$ & $2.4(0.9-5.9)$ & $1.9(0.7-5.2) ; 0.20$ \\
\hline \multicolumn{6}{|l|}{ History of UTI } \\
\hline Any previous UTI & $51(50)$ & $21(21)$ & $3.8(2.0-7.0)$ & $5.0(2.5-10.1)$ & $2.5(1.0-6.1) ; 0.04$ \\
\hline History of UTI previous year & $35(35) \neq$ & $11(11)$ & $4.4(2.1-9.2)$ & $5.4(2.4-12.1)$ & $3.0(1.1-8.2) ; 0.04$ \\
\hline
\end{tabular}

Data are presented as n (\%). *adjusted for sex; tadjusted for age; \#two missing values.

of these cases [27]. We therefore conclude the PelFls is a useful tool for such a case-control study, as is also illustrated by the high degree of interobserver agreement in the present study.

The strengths of our study are the inclusion of cases reflecting daily practice within the community setting of patients presenting with febrile UTI or acute pyelonephritis, and controls reflecting the same community of people seeking medical attention, reflecting daily primary healthcare practice.

Furthermore, all subjects were clinically and microbiologically well documented, with almost no missing data. The combination of pelvic floor assessment and urine cultures especially created robust data to support the above conclusions.

The limitations of our study are its relatively small sample size and the possibility of selection and recall bias. For sample size, it could therefore not be excluded that in specific subgroups there might indeed be a relationship between febrile UTI and PFD. However, the data are consistent with previous reports on other risk factors for pyelonephritis and UTIs in general. In this respect, selection bias is unlikely. We selected cases with febrile UTI for assessment of pelvic floor function only if this would have made sense clinically. Therefore patients with, for instance, an indwelling urinary catheter, were excluded, as was also done in the control group. In daily practice a similar selection would occur before considering a pelvic floor assessment. The response rate in the group of cases was lower than in the control group (67\% vs $91 \%$ ) and cases excluded on pre-set exclusion criteria were older and more often had an underlying urinary tract disorder. This raises concern that selection bias in the group of cases might have skewed the findings. We therefore evaluated the group on risk factors for PFD and found a positive association with underlying urinary tract disorder and a negative association with older age (point estimate of the OR 3.6 and 0.3 , respectively). The net outcome of these contradictory associations is uncertain, but it is reasonable to consider these effects as balanced. Hence, it is unlikely that we selectively excluded cases with PFD, as described in Fig. 1. However, residual selection bias cannot be excluded with certainty.

We used a case-control study design and this approach holds a risk of recall bias. In our setting, cases completed the PelFls after a diagnosis of febrile UTI, which might have enhanced the sensitivity in reporting symptoms of PFD. However, the severity of febrile UTI and the fact that cases were slightly older and more frequently had underlying comorbidity, might have clouded their memory, leading to reduced sensitivity in detecting PFD; again, the net effect is unclear but presumably neutral.

Controls were individuals seeking primary healthcare and 23\% (28\% in women and 18\% in men) of them were suspected to have PFD. This might also be a biased selection of the general healthy population, but the reasons for seeking medical care were unlikely to be associated with PFD. Moreover, based on symptoms assessed by interviews, as in our study, a large recent population study in women estimated the prevalence of PFD to be $24 \%$, which is similar to our estimate of $28 \%$ in women [28].

The risk factors we identified for febrile UTI or pyelonephritis were remarkably similar to previous reports of risk factors for pyelonephritis and UTIs [11,29-31]. Underlying comorbidity, especially urinary tract disorders and diabetes mellitus, and a history of UTI were associated with febrile UTI. Known risk factors like recent sexual intercourse, new sexual partner or use of spermicide, could not be assessed because these data were not collected [29]. Urinary incontinence or difficulty holding urine are associated with febrile UTI but, as this was part of the PelFls questionnaire, these risk factors were not analysed separately $[11,29]$.

Risk factors for the presence of PFD in adults could not be addressed by this study because there were too few cases with suspected PFD. Nevertheless, our results suggest a relationship with an underlying urinary tract disorder. In this study population, an underlying urinary tract disorder predominantly occurred in men, in particular $\mathrm{BPH}$. A possible explanation for the relationship between PFD and urinary tract disorder might therefore be that the LUTS associated with $\mathrm{BPH}$ are correlated with 
autonomic nervous system overactivity, and similar symptoms are listed in the PelFIs questionnaire that particularly predicts PFD in terms of overactive rest tone $[27,32]$.

Furthermore there was an inverse relationship between a history of UTI and PFD, whereas there was no association with asymptomatic bacteriuria. This strongly suggests that there is either no or an inverse relationship between UTIs and PFD in adults. This finding is rather counterintuitive because UTIs are one of the key features of dysfunctional voiding in children and so far, reports suggest that this is also true for adults $[17,21,22]$. Probably, as the PelFls questionnaire addresses three different domains of the pelvic floor, related to micturition, defecation and sexual function, the PFD noted in this cohort could have relied upon problems concerning defecation and sexual function, of which the latter might lead to sexual abstinence and thus a lower chance of developing UTIs [29]. Future studies are needed to address this issue further. Another explanation for the apparent discrepancy between children and adults for UTIs and PFD is that the studies in children are biased by selection, by which only children with recurrent UTI were referred to paediatric urologists and thus included in the studies on dysfunctional voiding. This issue is illustrated by the fact that in a general paediatric population with UTI there was no relation with the dysfunctional elimination syndrome [33]. Furthermore, in the largest cohort ever described of children referred to the paediatric urology service, the association between UTI and the dysfunctional elimination syndrome could only be shown in the subgroup of children with concurrent VUR $[34,35]$. In this respect, the results of the present study also suggest that PFD in the general population is not related to febrile UTI. Further studies are needed to evaluate whether this is also true for the subgroup of adults with an underlying urinary tract disorder, and in men with BPH in particular. However, VUR is a problem of the developing child, i.e. children are different from adults.

In summary, we showed that PFD is common in adults seeking healthcare but it does not seem to have a pathophysiological role in febrile UTI or acute pyelonephritis. These findings contradict the general belief that PFD is a considerable cause of complicated UTI in adults. This might have implications for future research on this topic, in particular the question of whether this is also true for specific subgroups of patients with underlying urinary tract disorder, and the development of guidelines for urological diagnostics in unexplained complicated UTIs.

\section{ACKNOWLEDGEMENTS}

We acknowledge the patients for their participation, the primary-care physicians and their staff for enrolment of patients and the co-investigators of the following participating hospitals: Groene Hart Hospital, Gouda: T. Koster, MD, PhD; Rijnland Hospital, Leiderdorp: N.M. Delfos, MD; Diaconessenhuis Leiden, Leiden: H.C. Ablij, MD; Medical Center Haaglanden, the Hague; E.M. Leyten, MD, PhD; Spaarne Hospital, Hoofddorp: G.H. WattelLouis, MD. These data were presented in part at the 48th Interscience Conference on Antimicrobial Agents and Chemotherapy/46th Infectious Disease Society of America Annual Meeting, Washington, DC, 25-28 October, 2008, Abstract 1874.

\section{CONFLICT OF INTEREST}

None declared.

\section{REFERENCES}

1 Brown P, Ki M, Foxman B. Acute pyelonephritis among adults: cost of illness and considerations for the economic evaluation of therapy. Pharmacoeconomics 2005; 23: 1123-42

2 Pinson AG, Philbrick JT, Lindbeck GH, Schorling JB. Fever in the clinical diagnosis of acute pyelonephritis. Am J Emerg Med 1997; 15: 148-51

3 Piccoli GB, Consiglio V, Colla L et al. Antibiotic treatment for acute 'uncomplicated' or 'primary' pyelonephritis: a systematic, 'semantic revision'. Int J Antimicrob Agents 2006; 28 (Suppl. 1): S49-63

4 Sandberg T, Kaijser B, Lidin-Janson G et al. Virulence of Escherichia coli in relation to host factors in women with symptomatic urinary tract infection. J Clin Microbiol 1988; 26: 1471-6

5 Johnson JR, Scheutz F, Ulleryd P, Kuskowski MA, O'Bryan TT, Sandberg T. Host-pathogen relationships among Escherichia coli isolates recovered from men with febrile urinary tract infection. Clin Infect Dis 2005; 40: 813-22

6 Otto G, Sandberg T, Marklund BI, Ulleryd P, Svanborg C. Virulence factors and pap genotype in Escherichia coli isolates from women with acute pyelonephritis, with or without bacteremia. Clin Infect Dis 1993; 17: 44856

7 Lundstedt AC, Leijonhufvud I, Ragnarsdottir B, Karpman D, Andersson B, Svanborg C. Inherited susceptibility to acute pyelonephritis: a family study of urinary tract infection. J Infect Dis 2007; 195: 1227-34

8 Chowdhury P, Sacks SH, Sheerin NS. Toll-like receptors TLR2 and TLR4 initiate the innate immune response of the renal tubular epithelium to bacterial products. Clin Exp Immunol 2006; 145: 346-56

9 Chromek M, Brauner A. Antimicrobial mechanisms of the urinary tract. $J \mathrm{Mol}$ Med 2008; 86: 37-47

10 Lipsky BA. Urinary tract infections in men. Epidemiology, pathophysiology, diagnosis, and treatment. Ann Intern Med 1989; 110: 138-50

11 Raz R, Gennesin Y, Wasser J et al. Recurrent urinary tract infections in postmenopausal women. Clin Infect Dis 2000; 30: 152-6

12 Nicolle LE. A practical guide to antimicrobial management of complicated urinary tract infection. Drugs Aging 2001; 18: 243-54

13 Grabe M, Bishop MC, BjerklundJohansen TE et al. Guidelines on urological infections. European Association of Urology. Available at: http://www.uroweb. org/nc/professionalresources/guidelines/online. Accessed April 2009

14 van Haarst EPAG, Heldeweg EA, Schlatmann TJ, van der Horst HJ. Evaluation of the diagnostic workup in young women referred for recurrent lower urinary tract infections. Urology 2001; 57: 1068-72

15 Ulleryd P, Zackrisson B, Aus G, Bergdahl $\mathrm{S}$, Hugosson J, Sandberg T. Selective urological evaluation in men with febrile urinary tract infection. BJU Int 2001; 88: 15-20

16 Davis K, Kumar D. Pelvic floor dysfunction: a conceptual framework for collaborative patient-centred care. $J A d v$ Nurs 2003; 43: 555-68

17 McKenna PH, Herndon CD. Voiding dysfunction associated with incontinence, vesicoureteral reflux and recurrent urinary tract infections. Curr Opin Urol 2000; 10: 599-606

18 Finer G, Landau D. Pathogenesis of urinary tract infections with normal 
female anatomy. Lancet Infect Dis 2004; 4: 631-5

19 Carlson KV, Rome S, Nitti VW. Dysfunctional voiding in women. J Urol 2001; 165: 143-7

20 Groutz A, Blaivas JG, Pies C, Sassone AM. Learned voiding dysfunction (nonneurogenic, neurogenic bladder) among adults. Neurourol Urodyn 2001; 20: 25968

21 Akkad T, Pelzer AE, Mitterberger M et al. Influence of intravesical potassium on pelvic floor activity in women with recurrent urinary tract infections: comparative urodynamics might lead to enhanced detection of dysfunctional voiding. BJU Int 2007; 100: 1071-4

22 Minardi D, Parri G, d'Anzeo G, Fabiani $A$, El AZ, Muzzonigro G. Perineal ultrasound evaluation of dysfunctional voiding in women with recurrent urinary tract infections. J Uro/ 2008; 179: 947-51

23 Voorham-van der Zalm PJ, Stiggelbout AM, Aardoom I et al. Development and validation of the pelvic floor inventories Leiden (PelFIs). Neurourol Urodyn 2008; 27: $301-5$

24 Rubin RH, Shapiro ED, Andriole VT, Davis RJ, Stamm WE. Evaluation of new anti-infective drugs for the treatment of urinary tract infection. Infectious Diseases Society of America and the Food and Drug Administration. Clin Infect Dis 1992; 15 (Suppl. 1): S216-27

25 Byrt T. How good is that agreement? Epidemiology 1996; 7: 561

26 Messelink B, Benson T, Berghmans B et al. Standardization of terminology of pelvic floor muscle function and dysfunction: report from the pelvic floor clinical assessment group of the International Continence Society. Neurourol Urodyn 2005; 24: 374-80

27 Voorham-van der Zalm PJ. Lycklama à Nijeholt GAB, Elzevier HW, Putter $\mathrm{H}$, Pelger RC. Diagnostic investigation of the pelvic floor: a helpful tool in the approach in patients with complaints of micturition, defecation, and/or sexual dysfunction. J Sex Med 2008; 5: 864-71

28 Nygaard I, Barber MD, Burgio KL et al. Prevalence of symptomatic pelvic floor disorders in US women. JAMA 2008; 300: 1311-6

29 Scholes D, Hooton TM, Roberts PL, Gupta K, Stapleton AE, Stamm WE. Risk factors associated with acute pyelonephritis in healthy women. Ann Intern Med 2005; 142: 20-7
$30 \mathrm{Hu}$ KK, Boyko EJ, Scholes D et al. Risk factors for urinary tract infections in postmenopausal women. Arch Intern Med 2004; 164: 989-93

31 Ulleryd P. Febrile urinary tract infection in men. Int J Antimicrob Agents 2003; 22 (Suppl. 2): 89-93

32 McVary KT, Rademaker A, Lloyd GL, Gann P. Autonomic nervous system overactivity in men with lower urinary tract symptoms secondary to benign prostatic hyperplasia. J Urol 2005; 174 : 1327-433

33 Shaikh N, Hoberman A, Wise B et al. Dysfunctional elimination syndrome: is it related to urinary tract infection or vesicoureteral reflux diagnosed early in life? Pediatrics 2003; 112: 1134-7

34 Chen JJ, Mao W, Homayoon K, Steinhardt GF. A multivariate analysis of dysfunctional elimination syndrome, and its relationships with gender, urinary tract infection and vesicoureteral reflux in children. J Uro/ 2004; 171: 1907-10

35 Feldman AS, Bauer SB. Diagnosis and management of dysfunctional voiding. Curr Opin Pediatr 2006; 18: 139-47

Correspondence: Cees van Nieuwkoop, Leiden University Medical Center, Department of Infectious Diseases, C5-P, P0 Box 9600, 2300 RC Leiden, the Netherlands.

e-mail: c.van_nieuwkoop@lumc.nl

Abbreviations: PelFIs, Pelvic Floor Inventories Leiden; PFD, pelvic floor dysfunction.

\section{APPENDIX}

The PelFls is a validated questionnaire developed to evaluate whether pelvic floor dysfunction should be suspected. The contents of this questionnaire can be divided into several domains regarding pelvic floor function that is micturition, defecation and sexual function. Within the following out of each specific domain sample questions of the PelFls are listed.

\section{Domain micturition}

How often on average do you urinate during the day?

$2-4 \times$ per day; $5-7 \times$ per day; $8-10 \times$ per day; more than $10 \times$ per day

How often on average do you urinate at night? never; 1-2 $\times$ per night; $3-4 \times$ per night; $>4 \times$ per night
How often do you feel the need to urinate? continually; every half hour; every hour; longer than $1 \mathrm{~h} ; 2-4 \mathrm{~h}$; Longer

Can you put off urinating if you are sitting quietly?

must run directly; for a few minutes; have good control; other. Please indicate:

Does the urine come in one spurt? never; seldom; sometimes; regularly; always; other. Please indicate:

Do you have to push when you urinate? never; seldom; sometimes; regularly; always; other. Please indicate:

\section{Domain urinary continence}

Are you ever incontinent?

yes; no

How much urine leaks?

drops; a small burst; a whole bladderful; other. Please indicate: ; not applicable

Do you have more leakage:

in the cold, yes, no; if a tap is running, yes, no; if you are nervous, yes, no; in the shower, yes, no

\section{Domain obstructive micturition}

Do you have the feeling after urinating that the bladder is completely empty?

never; seldom; sometimes; regularly; always; other. Please indicate:

Is urinating itself painful? never; seldom; sometimes; regularly; always; other. Please indicate:

When you have finished urinating and stand up, does it still dribble?

never; seldom; sometimes; regularly; always; other. Please indicate:

\section{Domain defecation}

How often on average per week do you have bowel movement in the daytime?

$<1 \times$ per week; $1-2 \times$ per week; $3-7 \times$ per week; $>7 \times$ per week; never; other. Please indicate:

What is the consistency of the stool? thin, watery; mushy; soft; hard; varying consistency; other. Please indicate: 
PELVIC FLOOR DYSFUNCTION IS NOT A RISK FACTOR FOR FEBRILE UTI IN ADULTS)

Do you ever have bright red bleeding during the bowel movement?

never; seldom; sometimes; regularly; always; other. Please indicate:

\section{Domain fecal incontinence}

Do you ever have bowel incontinence?

yes; no

Can you put off the urge to empty your bowel for $15 \mathrm{~min}$ ?

never; seldom; sometimes; regularly; always; other. Please indicate:

Do you feel that faeces is leaking? yes; no; sometimes; not applicable

Have you ever had skin irritation around the anus?

never; seldom; sometimes; regularly; always; other. Please indicate:
Have you ever had itch around the anus? never; seldom; sometimes; regularly; always; other. Please indicate:

\section{Domain constipation}

Whenever you go to the toilet to move your bowels, do you need more than 15 min for this?

never; seldom; sometimes; regularly; always; other. Please indicate:

Do you feel that the bowel is completely empty after the bowel movement? never; seldom; sometimes; regularly; always; other. Please indicate:

Do you feel that the stool is coming in pieces (several times consecutively)?

never; seldom; sometimes; regularly; always; other. Please indicate:
Do you have pain around the anus after a bowel movement?

never; seldom; sometimes; regularly; always; other. Please indicate:

\section{Domain sexual function}

Do you have sexual intercourse? yes; no

Do you have pain during intercourse? pain on penetration, yes, no, not applicable; pain deep inside; yes, no, not applicable

In addition to the above listed sample questions the PelFls includes specific questions for men and women. For men there are additional questions about erectile function and for women questions related to vaginal prolapse, menstrual cycle and history of pregnancies and deliveries. 
Copyright of BJU International is the property of Wiley-Blackwell and its content may not be copied or emailed to multiple sites or posted to a listserv without the copyright holder's express written permission. However, users may print, download, or email articles for individual use. 